Revista Tecné, Episteme y Didaxis: TED. Año 2014, Número Extraordinario. ISSN Impreso: 0121-3814, ISSN web: 2323-0126

Memorias, Sexto Congreso Internacional sobre Formación de Profesores de Ciencias. 08 al 10 de octubre de 2014, Bogotá

\title{
Aproximación a la reconstrucción de los conceptos de ácido y base a partir del análisis de situaciones ambientales problémicas: Experiencia de socialización del grupo de investigación Meq.
}

Lamus Antolínez, Gladys'; Lopera Pérez, Marisol² y Alzate Cano, María Victoria3

Categoría 1. Reflexiones y experiencias desde la innovación en el aula

\section{Resumen}

El grupo de investigación MEQ sistematiza la experiencia del VI Encuentro de maestros de Ciencias Naturales de básica primaria, secundaria y media; resalta este espacio académico como favorecedor de la construcción y reconstrucción de los conceptos ácido, base y $\mathrm{pH}$, y la transferencia del conocimiento en Química para la comprensión de situaciones ambientales problémicas, con el fin de movilizar aprendizajes significativos y dinamizar el trabajo de aula. Esta reflexión hace énfasis en las preguntas y respuestas de los participantes frente a la temática planteada, sus posturas y discursos durante la interacción y socialización. Se da protagonismo a la constitución de una red pedagógica para la enseñanza de la Química donde el intercambio de ideas, experiencias y el desarrollo personal y profesional son determinantes para impactar los procesos de enseñanza y aprendizaje.

\section{Palabras clave}

Aprendizaje Significativo, Ácido, base, situación de enseñanza problémica.

\section{Introducción}

Este ejercicio de reflexión hace referencia a la experiencia de formación con maestros de Ciencias Naturales y Química, realizado por el Grupo MEQ (Grupo de investigación Metodología de la Enseñanza de la Química) en el marco del desarrollo del VI encuentro de maestros MEQ llevado a cabo en el mes de octubre de 2013. Este encuentro tiene como antecedente las experiencias de enseñanza y aprendizaje de la Química, realizadas en el aula de clase por un

\footnotetext{
1 I. E. Concejo de Medellín. glamus1@hotmail.com

2 I. E. República de Honduras. marisolope@yahoo.com

3 Universidad de Antioquia. maria.alzate@udea.edu.co
} 
Revista Tecné, Episteme y Didaxis: TED. Año 2014, Número Extraordinario. ISSN Impreso: 0121-3814, ISSN web: 2323-0126

Memorias, Sexto Congreso Internacional sobre Formación de Profesores de Ciencias. 08 al 10 de octubre de 2014, Bogotá

grupo de maestros de básica primaria, secundaria y media durante 12 años, además del intercambio académico entre la Universidad y la escuela, la simbiosis entre pares, y los intereses de los maestros de Medellín y Antioquia que han participado en los cinco encuentros anteriores.

Enriquece éste proceso dos experiencias de aula cotidianas, desarrolladas por algunos integrantes del grupo en relación con el agua y los afluentes cercanos a sendas instituciones educativas, una rural y otra urbana. Se parte del esfuerzo por reconocer los objetos de estudio de la Química desde la aproximación ambiental y se involucran como posibilidad de movilizar aprendizajes significativos en los estudiantes.

Mediante diálogo en el grupo respecto a la enseñanza de los conceptos ácido y base, se concluyó que: los conceptos ácido y base están asociados sólo al cambio de color del papel indicador, no conceptualizados en términos de teorías químicas, y en caso de serlo se evidencia débil y confuso el acercamiento a los conceptos según las teorías de Arrhenius y de Brönsted-Lowry; se confunden con el concepto de pH; no se considera la presencia en medio acuoso del catión hidrógeno o del anión hidróxido; no claridad respecto a los términos de neutralización, hidrólisis y disociación; no utilización del lenguaje químico en términos de fórmulas moleculares y ecuaciones químicas para representar las respectivas disociaciones de los solutos en el medio acuoso.

Se llama la atención a considerar de un modo crítico el abordaje de la enseñanza desde una mirada aproblemática y descontextualizada de la realidad y se enfatiza la necesidad de plantear iniciativas para superar dicha situación didáctica.

Las Teorías pedagógicas, didácticas y disciplinares en las que se fundamenta la propuesta de enseñanza son: Aprendizaje Significativo de Ausubel (Ausubel (1980) y Moreira (2000)), Aprendizaje Significativo Crítico de Moreira (Moreira, 2005), las Categorías para la comprensión del conocimiento químico de Jensen (Jensen, 1998) y el lenguaje Químico de Jacob (Jacob, 2001).

El encuentro se plantea como objetivo general reconstruír conceptos y representaciones sobre ácido y base en medio acuoso a través de la discusión apoyada en situaciones problemas in situ, permitiendo a los docentes desaprender y reaprender nuevas concepciones en la enseñanza de los conceptos de interés. Como objetivos específicos se pretende: a) Identificar y 
Revista Tecné, Episteme y Didaxis: TED. Año 2014, Número Extraordinario. ISSN Impreso: 0121-3814, ISSN web: 2323-0126

Memorias, Sexto Congreso Internacional sobre Formación de Profesores de Ciencias. 08 al 10 de octubre de 2014, Bogotá

diferenciar los conceptos de ácido, base y pH en situaciones ambientales problémicas; b) Reconocer y diferenciar los conceptos de neutralización, hidrólisis y disociación; c) Re-apropiar la red conceptual que implica los conceptos de ácido, base y $\mathrm{pH}$; d) Utilizar la representación lingüística química en el tratamiento de situaciones de ácido y base y favorecer el planteamiento de situaciones que impliquen sustancias de carácter ácido o básico en contexto, y e) fomentar el trabajo colaborativo y cooperativo, la discusión, el análisis crítico y la argumentación en ciencias.

\section{Desarrollo}

La secuencia didáctica se orienta según el ciclo de aprendizaje de Jorba y Neus Sanmartí (1996), la cual plantea 4 momentos de aprendizaje que favorecen la regulación y autorregulación de los aprendizajes y la metacognición, importantes para la aproximación y reestructuración conceptual de los conceptos ácido y base. A continuación se describe la secuencia del encuentro en el esquema 1. 
Revista Tecné, Episteme y Didaxis: TED. Año 2014, Número Extraordinario. ISSN Impreso: 0121-3814, ISSN web: 2323-0126

Memorias, Sexto Congreso Internacional sobre Formación de Profesores de Ciencias. 08 al 10 de octubre de 2014, Bogotá

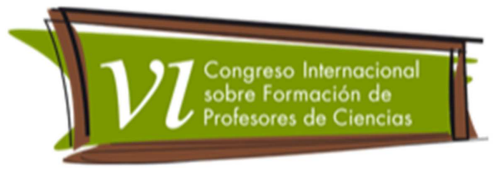

Esquema 1. Secuencia metodológica del VI encuentro de maestros Meq.

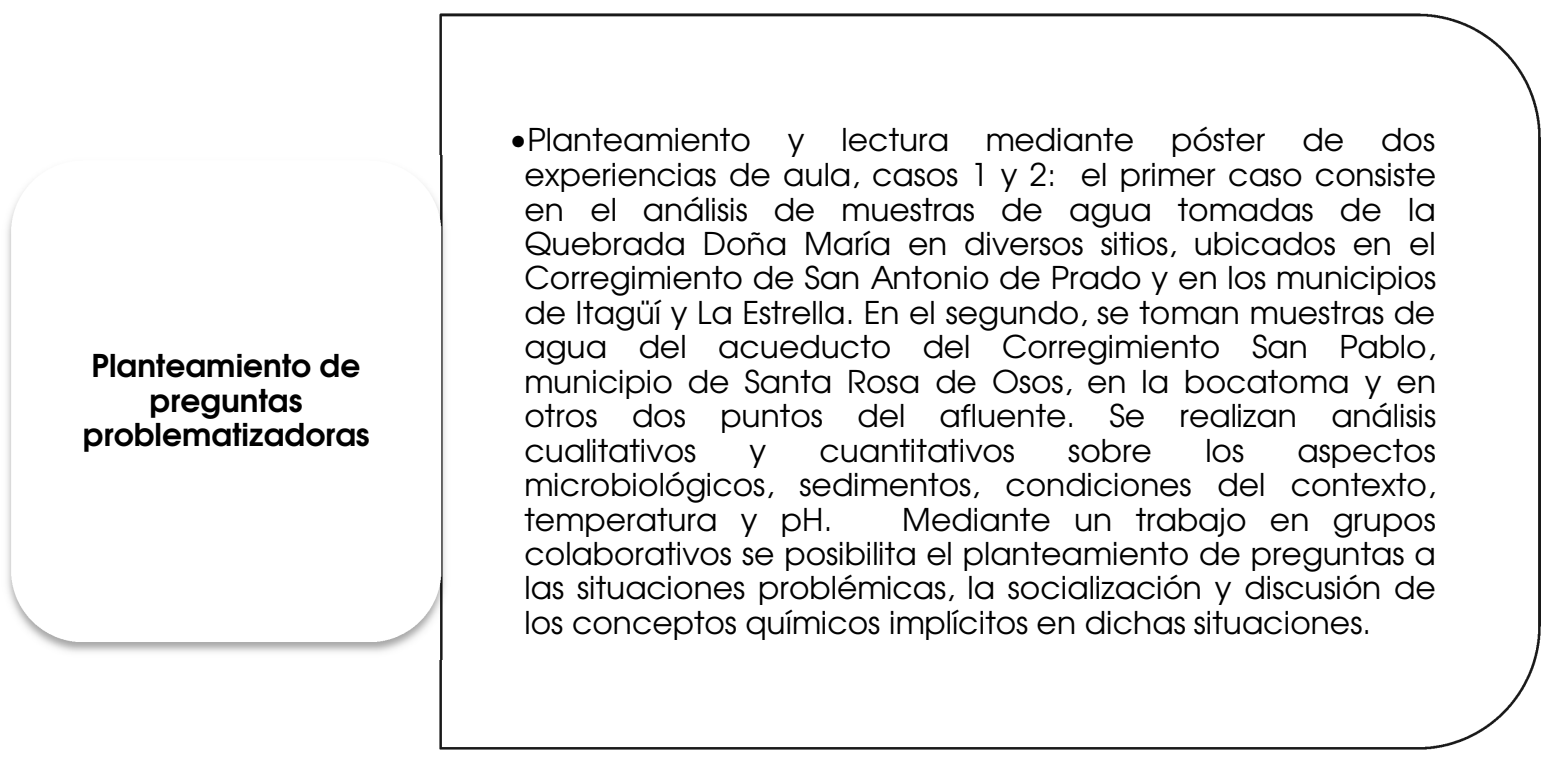

Exploración de ideas previas y contrastación de las representaciones de los docentes
- De acuerdo a la práctica docente y al dominio del saber químico de interés, se pide a los maestros responder las siguientes preguntas: ¿Qué entiendes por ácido? Escribe una ecuación química para una situación conocida. ¿Qué entiendes por base? Escribe la ecuación química para una situación conocida. ¿Qué entiendes por pH? ¿Puedes decir qué entidad química $\mathrm{O}$ entidad molecular es la responsable del pH 7.2? ¿Qué entiendes por neutralización? ¿Qué entiendes por hidrólisis? ¿Qué entiendes por disociación? 
Revista Tecné, Episteme y Didaxis: TED. Año 2014, Número Extraordinario. ISSN Impreso: 0121-3814, ISSN web: 2323-0126 Memorias, Sexto Congreso Internacional sobre Formación de Profesores de Ciencias. 08 al 10 de octubre de 2014, Bogotá
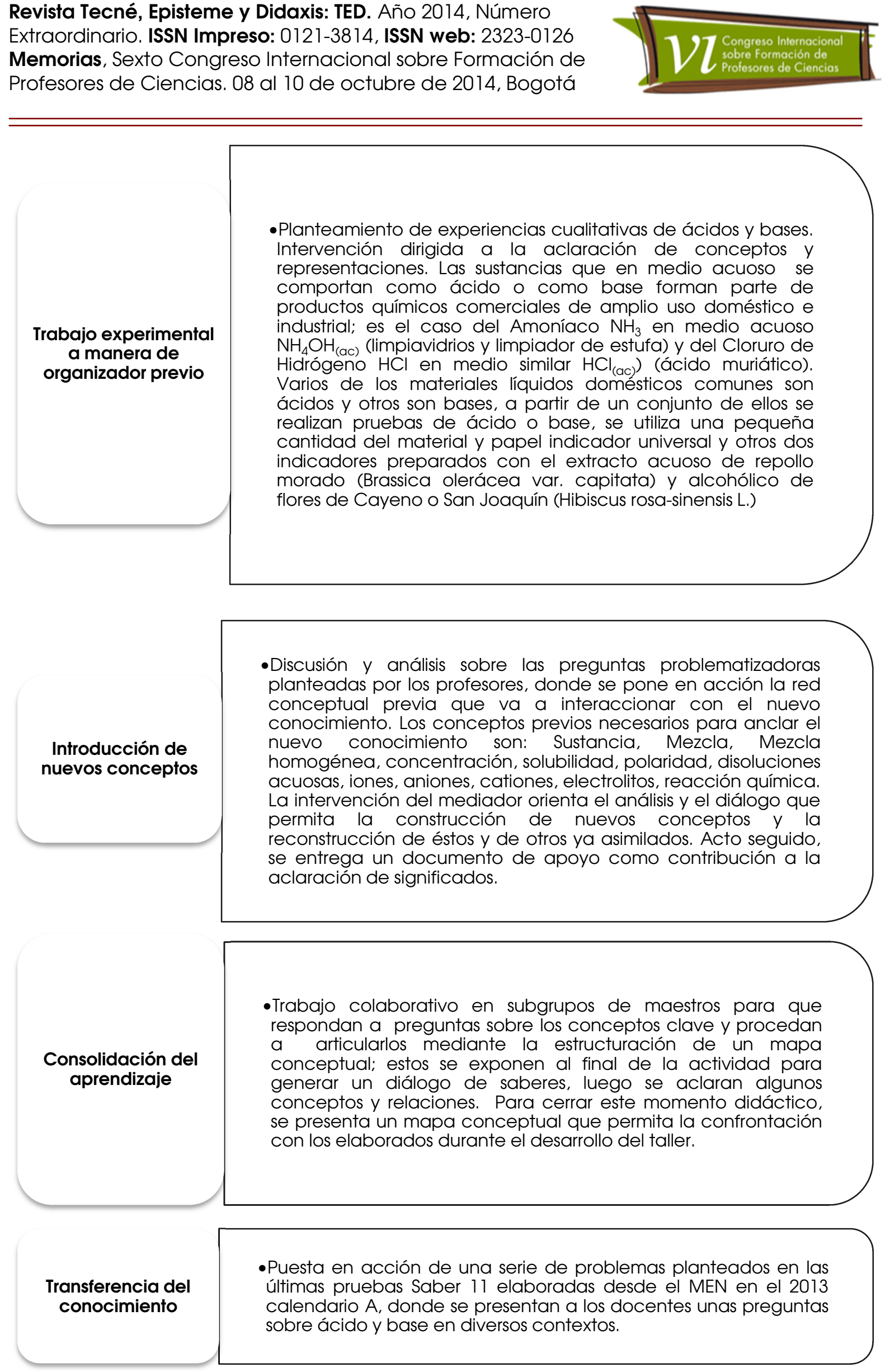
Revista Tecné, Episteme y Didaxis: TED. Año 2014, Número Extraordinario. ISSN Impreso: 0121-3814, ISSN web: 2323-0126

Memorias, Sexto Congreso Internacional sobre Formación de Profesores de Ciencias. 08 al 10 de octubre de 2014, Bogotá

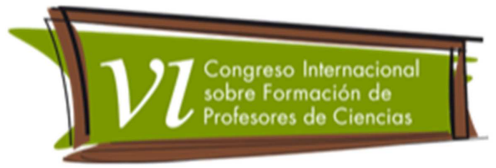

\section{Hallazgos y conclusiones}

La síntesis de los resultados obtenidos en el VI Encuentro de Maestros MEQ se realiza teniendo en cuenta cuatro categorías de análisis que son: la disciplinar, pedagógica-didáctica, metodológica y actitudinal/motivacional, y se especifican en la tabla 1.

Tabla 1. Hallazgos y conclusiones del VI Encuentro de maestros MEQ

\begin{tabular}{|c|c|}
\hline Categorías de análisis & $\begin{array}{l}\text { Hallazgos } \\
\end{array}$ \\
\hline Disciplinar & $\begin{array}{l}\text { - El encuentro favoreció la reconstrucción y construcción del } \\
\text { conjunto de conceptos sustancia, mezcla, medio acuoso, ácido, } \\
\text { base, pH, disociación, neutralización, hidrólisis, y del lenguaje } \\
\text { químico; mediados por las dos situaciones de aprendizaje en } \\
\text { contexto. } \\
\text { - Se posibilitó la puesta en acción de los conceptos químicos } \\
\text { expresando de modo cualitativo y cuantitativo los conceptos de } \\
\text { ácido, base y pH. } \\
\text { - Los docentes plantearon preguntas alusivas al tipo de residuos } \\
\text { que se disponen en los afluentes, tales como aguas residuales } \\
\text { domésticas, industriales o agrícolas y la alteración de las } \\
\text { características físicas, químicas y biológicas; el reconocimiento } \\
\text { de variables como la temperatura, reacciones químicas que se } \\
\text { presentan, procesos biológicos, concentración de oxígeno, } \\
\text { precipitación de compuestos y formación de depósitos. Así } \\
\text { mismo, se dejan ver cuestionamientos sobre los parámetros } \\
\text { químicos que se pueden determinar en las aguas como dureza, } \\
\text { sulfatos, fosfatos, cloruros, hierro, alcalinidad, acidez y sustancias } \\
\text { que puedan estar disueltas y disociadas o no en el agua, y las } \\
\text { insolubles en ella. } \\
\text { Se evidenció que ninguna de las preguntas problematizadoras } \\
\text { especula sobre reacciones químicas puntuales ocurridas en los } \\
\text { afluentes, ni de la relación entre fenómenos locales y regionales } \\
\text { con otros globales. } \\
\text { Se observaron en algunos mapas conceptuales la } \\
\text { desarticulación de los conceptos ácido, base, pH y } \\
\text { neutralización desde las teorías de Arrhenius y Brönsted-Lowry. } \\
\text { En otros mapas, fue clara la aproximación a los conceptos desde } \\
\text { las distintas teorías y se expresan fórmulas y ecuaciones químicas. } \\
\text { Durante la socialización emergieron preguntas tanto didácticas } \\
\text { como disciplinares y metodológicas desde la ecología, la } \\
\text { biología y los asuntos químico-físicos, lo cual da cuenta de la } \\
\text { comprensión interdisciplinar de los fenómenos como complejos, } \\
\text { dinámicos y multicausales. }\end{array}$ \\
\hline Pedagógica-didáctica & $\begin{array}{l}\text { - El trabajo experimental y la elaboración de mapas conceptuales } \\
\text { permitieron la regulación y autorregulación de los aprendizajes } \\
\text { durante el proceso. }\end{array}$ \\
\hline
\end{tabular}


Revista Tecné, Episteme y Didaxis: TED. Año 2014, Número Extraordinario. ISSN Impreso: 0121-3814, ISSN web: 2323-0126

Memorias, Sexto Congreso Internacional sobre Formación de Profesores de Ciencias. 08 al 10 de octubre de 2014, Bogotá

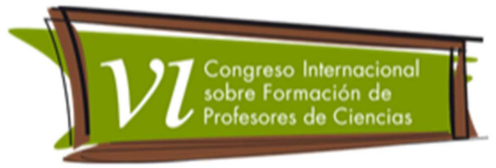

\begin{tabular}{|c|l|l|}
\hline & $\begin{array}{l}\text { Los docentes reconocieron sus ideas previas y se hicieron más } \\
\text { conscientes de los obstáculos epistemológicos para abordarlos. } \\
\text { Los profesores asumieron la reconstrucción de los conceptos } \\
\text { ácido, base, pH, neutralización, hidrólisis y disociación. } \\
\text { - Fue reiterativo el uso del lenguaje común y la dificultad de } \\
\text { poner en acción el lenguaje químico. }\end{array}$ \\
\hline Metodológica & $\begin{array}{l}\text { El trabajo colaborativo y cooperativo favoreció el diálogo entre } \\
\text { pares, la explicitación de las ideas previas, la negociación de } \\
\text { significados y llegar a consensos en la deconstrucción y } \\
\text { reconstrucción de los conceptos; y la comunicación de } \\
\text { experiencias de aula y el análisis crítico de sus prácticas } \\
\text { pedagógicas. } \\
\text { Los docentes percibieron las situaciones problémicas } \\
\text { presentadas como pertinentes y susceptibles de transferir en el } \\
\text { aula. } \\
\text { La participación de los docentes en el trabajo experimental } \\
\text { dinamizó el taller y favoreció el aprehendizaje de los conceptos } \\
\text { químicos formales. } \\
\text { Se evidenció que cuando los maestros logran reconocer sus } \\
\text { obstáculos epistemológicos impactan su quehacer docente. } \\
\text { Los docentes consideraron que esta clase de experiencias y } \\
\text { espacios de confrontación didáctica ayudan a cualificar el } \\
\text { trabajo de aula, los enriquecen, flexibilizan y les posibilita el } \\
\text { desarrollo de experiencias de enseñanza potencialmente } \\
\text { significativas. }\end{array}$ \\
\hline Actitudinal/motivacional
\end{tabular}

\section{Referencias Bibliográficas}

Ausubel, D. P. (1980). Psicología Educativa. Un punto de vista cognoscitivo. Editorial Trillas, 2aㅗ reimpresión, México, pág. 1230.

Grupo MEQ. (2013). Reconstrucción de los conceptos de acidez y basicidad a partir del análisis de situaciones ambientales problémicas. Documento preparado como material de apoyo para el VI encuentro de Maestros MEQ. Medellín, octubre 21. pág. 19.

Jacob, C. (2001). Analysis and Synthesis, Interdependent Operations in Chemical Language and Practice, HYLE - International for Philosophy of Chemistry, pág. 7, 1, 31-50.

Jensen, W. B. (1998). Logic, History, and the Chemistry Textbook I, Does Chemistry have a Logical Structure? Journal of Chemical Education, pág. 75, 6, 679685. 
Revista Tecné, Episteme y Didaxis: TED. Año 2014, Número Extraordinario. ISSN Impreso: 0121-3814, ISSN web: 2323-0126

Memorias, Sexto Congreso Internacional sobre Formación de Profesores de Ciencias. 08 al 10 de octubre de 2014, Bogotá

Jorba, A, J. y Sanmarti, N. (1996). Enseñar, aprender y evaluar: un proceso de regulación continua. Propuestas didácticas para las áreas de Ciencias de la Naturaleza y Matemáticas. MEC, en prensa. Barcelona. España. pág. 321.

MEN (Ministerio de Educación Nacional) 2013. Pruebas Saber 11. Calendario A. http://www.icfes.gov.co/examenes/index.php?option=com_content\&view= article\&id=156\&catid=21\&ltemid=206 recuperado septiembre 6 de 2013, pág. 50.

Moreira, M. A. (2000). Aprendizaje Significativo: Teoría y Práctica, aprendizaje Visor. Madrid, pág. 100.

Moreira, M. A. (2005). Aprendizaje Significativo Crítico, Impresos Portão, Porto Alegre, pág. 47. 